REVIEW

\title{
Mucosal immunology of vaccines against pathogenic nasopharyngeal bacteria
}

\author{
Q Zhang, A Finn
}

J Clin Pathol 2004;57:1015-1021. doi: 10.1136/jcp.2004.016253

The introduction of Haemophilus influenzae type $b$ conjugate vaccines during the 1990s was followed by dramatic decreases both in the incidence of Haemophilus influenzae type $b$ related invasive disease and in nasopharyngeal carriage of the organism. The extent of this effect has been influenced by the fact that Haemophilus influenzae type $b$ conjugate vaccines reduce nasopharyngeal carriage and induce herd immunity. Based on the success of Haemophilus influenzae type $b$ conjugate vaccines, chemical conjugation has been applied to the development of pneumococcal and meningococcal polysaccharide conjugate vaccines. Evidence has begun to accumulate that these new polysaccharide based conjugate vaccines can also reduce nasopharyngeal carriage and can induce immune responses at the local mucosal level, which may be responsible for these effects. This article reviews recent studies on mucosal immune responses induced by polysaccharide based vaccines and some protein vaccine antigens against several pathogenic nasopharyngeal bacteria, and discusses the mechanisms and functions of these immune responses that may help our understanding of mucosal immune responses to both immunisation and infection.

Correspondence to: Dr A Finn, Department of Clinical Sciences South Bristol, Institute of Child Health, University of Bristol, UBHT Education Centre, Upper Maudlin Street, Bristol BS2 8AE UK; Adam.Finn@bristol. ac.uk

Accepted for publication 1 May 2004
E very year, millions of people die of infectious diseases worldwide, most of which are caused by pathogens invading the host via mucosal surfaces, including the respiratory tract. Several new mucosal vaccines against respiratory infections are under development. Live attenuated mucosal influenza vaccine has been licensed in the USA, but it will probably be some time before others go into general use. Recent studies show that parenterally administered capsular polysaccharide (PS) based vaccines can induce mucosal immune responses. These immune responses may be important both in the prevention of invasive diseases and in the reduction of upper respiratory carriage of pathogens.

Haemophilus influenzae type b, Streptococcus pneumoniae, and Neisseria meningitidis colonise the mucosa of the human upper respiratory tract along with other opportunistic pathogens and commensal bacteria. The nasopharynx is presumed to be the main site of invasion into the bloodstream. The transmission of these bacteria primarily between asymptomatic carriers is through droplet spread or contact with respiratory secretions. To be effective against colonisation, vaccines must induce local immune responses, which promote elimination of the pathogen, break the chain of transmission, and induce herd immunity.

It has long been recognised that serum antibodies to capsular PS of some bacteria including $H$ influenzae type b, $S$ pneumoniae, and $N$ meningitidis are protective against invasive disease. Unconjugated PS vaccines have been available for many years and have received some use in adults. However, because they induce a $\mathrm{T}$ cell independent B cell response, they are poorly immunogenic in young children, and in adults only induce relatively short term protection. ${ }^{1-3}$

\section{"Conjugate vaccines can induce effective primary immune responses in young children and provide longterm protection through the induction of immunological memory"}

Conjugate vaccine technology, where a polysaccharide antigen is coupled chemically to a protein carrier, either by direct linkage or by indirect coupling via diamino spacer molecules, can render the PS specific immune response $\mathrm{T}$ cell dependent. With the help of $\mathrm{T}$ cell derived factors, the antigen specific $\mathrm{B}$ cells produce a much enhanced antibody response. Several protein carriers have been used including tetanus toxoid (TT), diphtheria toxoid, mutant diphtheria toxin (CRM197), and the outer membrane protein of $N$ meningitidis. Different conjugate vaccines with different protein carriers vary in their immunogenicity. Whereas some conjugate vaccines (for example, $H$ influenzae type b polyribosyl phosphate-outer membrane protein) have been shown to be immunogenic after a single dose in infancy, other $H$ influenzae type b vaccines with different protein carriers need two to three doses to have appreciable immunogenicity. ${ }^{4}$ The TT carrier has been suggested to be a better primer than CRM197 for immune responses induced by the conjugate meningococcal C vaccines. ${ }^{5}$ Conjugate vaccines with different carrier proteins have also been shown to induce antibody responses with varying avidity. ${ }^{7}$

Conjugate vaccines can induce effective primary immune responses in young children and provide longterm protection through the induction of immunological memory. ${ }^{8-11}$ The

Abbreviations: MenC, meningococcal serogroup C; PS, polysaccharide; $\Pi$, tetanus toxoid 
introduction of $H$ influenzae type b conjugate vaccines in several countries in the 1980s and 1990s was followed by a rapid reduction in $H$ influenzae type b related invasive disease and nasopharyngeal carriage. After the success of $H$ influenzae type b conjugate vaccines, the same approach has been applied to the development of new conjugate vaccines against $S$ pneumoniae ${ }^{12}$ and $N$ meningitidis. ${ }^{13}$ Early results have suggested that these vaccines may be effective against mucosal carriage of the vaccine serotypes.

Despite the effectiveness of polysaccharide-protein conjugate vaccines, protection is restricted to those serotypes of bacteria covered by the vaccine serotypes, and it is possible that they may be replaced in the mucosa by other serotypes after immunisation. In the case of $N$ meningitides group $\mathrm{B}$, the polysaccharide capsule is a very poor immunogen and there are theoretical risks related to rendering it immunogenic by conjugation. For these reasons, efforts have also been made in the past few years to identify effective protein vaccine antigens that could have a broad spectrum of serotype coverage among these bacteria, especially $S$ pneumoniae, which has over 90 serotypes.

Here, we review recent studies on mucosal immune responses induced by polysaccharide based vaccines and some protein vaccine antigens against several pathogenic nasopharyngeal bacteria, and discuss the mechanisms and functions of these immune responses that might help our understanding of mucosal immune responses to both immunisation and infection.

\section{HAEMOPHILUS INFLUENZAE TYPE B VACCINES}

Haemophilus influenzae type b is a Gram negative coccobacillus that colonises the upper respiratory tract of young children. There is no known non-human reservoir. Before the widespread use of conjugate vaccines, $H$ influenzae type $\mathrm{b}$ was a leading cause of serious infections, including meningitis, in children. Many children carried $H$ influenzae type b at some time during the first 5 years of life for periods varying from days to months. ${ }^{14-16}$ Although $H$ influenzae type b polysaccharide vaccines have little or no effect on carriage rates, ${ }^{17} 18$ conjugate vaccines have been shown to reduce nasopharyngeal carriage of $H$ influenzae type $b .{ }^{16}{ }^{18-21}$ These variations are probably caused by the differences in the local mucosal immune responses induced by the two types of vaccine. The reduction in carriage rate of $H$ influenzae type b but not nontype b H influenzae or $S$ pneumoniae ${ }^{16}$ after the introduction of $H$ influenzae type b conjugate vaccines suggests that these vaccines induce antigen specific local immune responses.

Salivary anti- $H$ influenzae type b PS IgA antibodies can be detected after immunisation with $H$ influenzae type b PS vaccines and after $H$ influenzae type b infections, ${ }^{22-24}$ although they decline rapidly over time. IgG is rarely detected in these conditions. Kauppi et al measured IgA and IgG antibodies to $H$ influenzae type b polysaccharide in the saliva of 7 to 19 month old children after immunisation with two or three doses of $H$ influenzae type b conjugate vaccines and showed that salivary antibodies were produced after two doses and increased further in concentration after three doses. ${ }^{25}$ Both the presence and concentrations of specific salivary IgG were significantly correlated with serum IgG, findings which suggest that salivary anti- $H$ influenzae type b IgG antibodies are derived from serum. PS specific salivary IgA correlated with salivary secretory component concentrations, but not with serum anti-H influenzae type b PS IgA concentrations, suggesting that the PS specific salivary IgA was locally produced in secretory form.

It is probable that these mucosal anti- $H$ influenzae type b PS antibodies play an important role in the reduction, eradication, or prevention of nasopharyngeal carriage, although the relative contributions of local IgA and IgG are yet to be defined. In an infant rat model, intranasally administered anti-H influenzae type b PS monoclonal antibodies and postimmunisation serum or milk samples enriched with either $H$ influenzae type b PS specific IgG or secretory IgA significantly reduced nasopharyngeal colonisation with $H$ influenzae type $\mathrm{b}$, suggesting that both $\operatorname{IgG}$ and secretory IgA can be protective against carriage. ${ }^{26}{ }^{27} \mathrm{~A}$ murine anti$H$ influenzae type b PS monoclonal antibody has also been shown to inhibit the adherence of encapsulated $H$ influenzae type $b$ to human oropharyngeal epithelial cells in an in vitro system, and also to inhibit the growth of $H$ influenzae type $b .^{28}$ The effects seemed to be anti-PS antibody specific because antibodies to $H$ influenzae type $\mathrm{b}$ outer membrane proteins and lipopolysaccharide did not inhibit colonisation in this model. ${ }^{28}$ The mechanisms by which these antibodies inhibit $H$ influenzae type $\mathrm{b}$ adherence are still unclear. Because capsular PS is not known to be a bacterial adhesin, the antibody mediated inhibition of bacterial adherence may be through steric interference with the adhesion of $H$ influenzae type b to epithelial cells. It is known that binding of antibodies to capsular PS results in the formation of a gel structure around the bacteria, a process known as the Quellung reaction. It is not known whether the concentration of complement at the mucosal surface in humans is high enough for complement mediated bactericidal lysis or opsonophagocytosis by local macrophages and/or polymorphonuclear cells. ${ }^{29}{ }^{30}$ However, it has been shown that during colonisation with $H$ influenzae, the local distribution of complement, IgG, and leucocytes within the mucosa is more prominent. $^{31}$ Because parenteral PS-protein conjugate vaccines against $H$ influenzae type $\mathrm{b}$ have had such comprehensive success, there has been no incentive to investigate alternative vaccine antigens or routes of administration.

\section{STREPTOCOCCUS PNEUMONIAE VACCINES}

Streptococcus pneumoniae is a ubiquitous Gram positive commensal and pathogen in humans, which causes disease predominantly in children and the elderly. Asymptomatic nasopharyngeal carriage of pneumococci is common in infants and young children and is related both to disease and the spread of the pathogen. ${ }^{32}{ }^{33}$ Secretory IgA antibodies to pneumococcal capsular PS can be detected in mucosal secretions in acute and convalescent nasopharyngeal aspirates from patients with otitis media, ${ }^{34}$ and emerge in association with previous colonisation with $S$ pneumoniae, ${ }^{35}$ although mucosal IgG and IgM antibodies are rarely detected in these patients. The local secretory IgA response may develop as early as 6 months of age, which is earlier than serum responses are usually detectable, suggesting that mucosal immunity to bacterial polysaccharides after carriage can develop in the absence of systemic immunity. ${ }^{34}{ }^{36}$ However, it is not known whether the mucosal IgA antibodies that develop after colonisation with pneumococcus can prevent subsequent carriage. Although studies examining whether pneumococcal polysaccharide vaccines can prevent otitis media produced unimpressive results, ${ }^{37-40}$ recent efficacy trials indicate that conjugate pneumococcal vaccines may prevent some otitis media caused by pneumococcus, suggesting that effective local mucosal immunity in the middle ear can be induced by such vaccines ${ }^{41-43}$ However, one recent study of a combined conjugate and polysaccharide regimen showed no protection in children with recurrent otitis media. ${ }^{44}$

Vaccination with pneumococcal PS did not alter carriage rates in healthy children in one study. ${ }^{45}$ However, pneumococcal conjugate vaccines have been shown not only to be immunogenic and protective against invasive disease in children, ${ }^{41}{ }^{46}$ but also to reduce nasopharyngeal carriage rates of vaccine serotypes of pneumococci for at least 12-18 
months. ${ }^{32}{ }^{47-50}$ In one study, the siblings of vaccinated children attending day care centres had reduced carriage rates of vaccine serotypes, in addition to reduced rates of upper respiratory tract infections when compared with the siblings of unvaccinated children ( $\mathrm{R}$ Dagan et al. Immunization of toddlers attending day care centers (DCCs) with a 9-valent pneumococcal vaccine (PncCRM9) reduces transmission of Streptococcus pneumoniae and antibiotic resistant $S$ pneumoniae to their younger siblings [abstract]. 40th Interscience Conference of Antimicrobial Agents and Chemotherapy, Toronto, Canada 2000), suggesting that the reduction of carriage in vaccinated children can lead to interruption of transmission and thus herd immunity, as recently shown in the USA. ${ }^{51}$ Although the reduction of carriage of vaccine types may be accompanied by a rise in the incidence of carriage and mucosal disease (otitis media) with non-vaccine serotypes, ${ }^{42}{ }^{50}$ conjugate vaccination may nevertheless result in a reduction of the serotypes most commonly associated with invasive disease, because most invasive strains are among the serotypes included in the conjugate vaccines..$^{50}$ The conjugate vaccine serotypes are also those most frequently found to be antibiotic resistant, so the vaccine can be expected to impact upon resistance. ${ }^{50}$

\section{"Recent efficacy trials indicate that conjugate pneumo- coccal vaccines may prevent some otitis media caused by pneumococcus, suggesting that effective local mucosal immunity in the middle ear can be induced by such vaccines"}

As with $H$ influenzae type $b$, the effects of pneumococcal conjugate vaccine on carriage are presumably the result of specific mucosal immune responses. Anticapsular IgA and IgG antibodies in saliva have been detected after immunisation with pneumococcal conjugate vaccines. ${ }^{52-56}$ Although mucosal antibody responses after a priming course of three vaccine doses in infancy are often not demonstrable, they are more consistently present at 13 or 14 months after either a polysaccharide or a conjugate vaccine booster. Significantly higher salivary IgA antibody concentrations after such booster immunisations than after primary courses provide some evidence of the induction of mucosal immunological memory, ${ }^{52}$ although, particularly where conjugate boosters were used, this change may be the result of immunological maturation during the 1st year of life. ${ }^{56}$ The similar pattern seen for IgG responses in saliva presumably reflects systemic immunological memory as manifested in serum. It is still unclear how long these antibodies last, to what extent the vaccination can prime for mucosal memory-type responses upon nasal exposure to pneumococcus, and whether these mucosal antibodies can reduce nasopharyngeal carriage. Recent data from our laboratory show that two to three years after infant vaccination with a seven valent pneumococcal conjugate vaccine, salivary IgG antibodies to most serotypes were detectable more frequently than in unvaccinated controls of similar age. ${ }^{57}$ This suggests that the conjugate vaccine can induce long lasting salivary IgG responses, although the degree to which re-exposure to nasal carriage is required to maintain these differences is not yet clear. In contrast, detection rates for salivary IgA antibodies to most serotypes were comparable in immunised children and unimmunised controls. Thus, children at 2-4 years of age, $^{57}$ and younger children, ${ }^{35}$ can mount serotype specific mucosal anticapsular IgA responses in the absence of vaccination, presumably in response to nasal exposure to colonising organisms. Perhaps such mucosal IgA responses develop with age and exposure, and may be an important defence mechanism in both immunised and unimmunised individuals. ${ }^{58}$

Despite the effectiveness of pneumococcal conjugate vaccines in preventing pneumococcal invasive diseases and the promising results in reducing nasopharyngeal carriage of vaccine serotypes, the high cost, limited serotype coverage, and associated increases in carriage rates of non-vaccine serotypes ${ }^{47}{ }^{50}$ have promoted efforts to find effective pneumococcal protein vaccines that might protect against multiple serotypes. Several novel pneumococcal proteins are currently under investigation, including choline binding protein $\mathrm{A}$, pneumococcal surface protein A, pneumolysin, and pneumococcal surface adhesin A. ${ }^{59}$ Studies in mice have shown that immunisation with choline binding protein A, pneumococcal surface adhesin $\mathrm{A}$, or both can prevent nasopharyngeal carriage, suggesting that they may be vaccine candidates against pneumococcal carriage. ${ }^{601}$ Serum and salivary antibodies to some of the proteins have been detected in healthy children and patients with otitis media. ${ }^{62}{ }^{63}$ We have demonstrated the presence of antibody secreting cells to these proteins in adenoidal B cells from children and have shown that these cells can be stimulated to proliferate by the same proteins in vitro. ${ }^{64}$ Although there are limited data on whether these antigen specific antibodies are protective, a recent study in an experimental model of human colonisation of pneumococcus in healthy adults has suggested that a $22 \mathrm{kDa}$ protein fragment of pneumococcal surface protein A may induce both systemic IgG and mucosal secretory IgA responses, which may prevent pneumococcal carriage in humans. ${ }^{65}$

\section{NEISSERIA MENINGITIDIS VACCINES}

Neisseria meningitidis is an important cause of meningitis and septicaemia in children. Human nasopharyngeal mucosa is the natural reservoir of $N$ meningitidis, and the organism is transferred from person to person through direct contact or via respiratory secretions. The carriage of $N$ meningitidis in the nasopharynx in otherwise healthy humans has long been recognised. ${ }^{66}$ The close relation between the carriage rate in a population and the onset of an epidemic suggests that the treatment of carriage could influence the incidence of disease. ${ }^{67}$ Three serogroups (A, B, and C) of $N$ meningitidis account for most meningococcal disease worldwide. In the UK, although serogroup B is the most prevalent cause of invasive disease, the increase in group $\mathrm{C}$ cases during the 1990s caused great public concern, which led to the national vaccination programme for children starting in 1999 using the newly licensed meningococcal serogroup $\mathrm{C}$ (MenC) conjugate vaccines. These conjugate vaccines are immunogenic in children and induce primary and memory-type responses in serum. ${ }^{68-70}$ Serogroup C meningococcal disease is now in steep decline in the $\mathrm{UK}^{71}$ and there was a significant fall in the carriage rate of group C meningococcus in 14 to 17 year old students a year after immunisation, ${ }^{72}$ suggesting that effective local immunity was induced.

Meningococcal PS based vaccines induce the production of mucosal IgA and IgG antibodies in young adults and adolescents. ${ }^{73}$ Compared with a meningococcal A and C PS vaccine, a conjugate MenC-CRM197 vaccine induced significantly higher salivary IgG responses than a MenC PS vaccine containing a five times larger dose of capsular antigen, although there were no significant differences between salivary IgA responses to the two vaccines. ${ }^{73}$ In young adults, both MenC PS and conjugate vaccines induce significant production of mucosal antibodies in saliva, ${ }^{74}$ although salivary anti-MenA and anti-MenC PS antibodies were detected in many subjects before immunisation, perhaps as a result of previous exposure or colonisation with these or antigenically related bacteria. ${ }^{74}$ In infants, mucosal 
IgG antibodies were seen after primary immunisation with MenC conjugate vaccines, but salivary IgA responses after three doses are generally poorer and vary between different vaccines. $^{75} 76$

\section{"There was a significant fall in the carriage rate of group $\mathrm{C}$ meningococcus in 14 to 17 year old students a year after immunisation, suggesting that effective local immu- nity was induced"}

We have recently found that good serum primary and booster responses after one and two dose priming courses of MenC-tetanus conjugate vaccine ${ }^{77}$ and a single priming dose may also induce better mucosal responses than two or three doses. ${ }^{78}$ Because mucosal anti-PS antibodies tend to decline rapidly to near prevaccination values after six to 12 months, ${ }^{73}$ the protection provided by these antibodies may be short term unless mucosal immunological memory is induced. However, this remains controversial at least for mucosal IgA; IgG memory is demonstrable at the mucosal level, presumably a reflection of the anamnestic serum IgG response. Nurkka et al failed to demonstrate mucosal IgA memory in saliva to group A and C PS in 4-5 year old Gambian children who had received MenA/C conjugate vaccine in infancy. ${ }^{79}$ However, results from our recent study on infants primed with a MenC conjugate vaccine (with TT carrier) and boosted with a low dose of MenC PS at 13 months show a memory type of response both for mucosal $\operatorname{IgA}$ and $\operatorname{IgG} .^{78}$ The induction of mucosal memory responses may vary with the nature of the antigens, different vaccine dose regimens, schedules, age, and route of immunisation, and perhaps also previous exposure to pathogens. ${ }^{74}$

\section{MECHANISMS OF MUCOSAL IMMUNITY INDUCED BY PARENTERAL VACCINATION}

Both PS IgAl and IgA2 subclasses are detectable after vaccination. ${ }^{80}$ The IgA2 subclass of IgA antibodies may provide some functional advantage in specific mucosal immune responses over IgAl as a result of structural differences that make IgA2 relatively resistant to IgAl protease activity..$^{81}$ Haemophilus influenzae type b, $S$ pneumoniae, and $N$ meningitidis can produce IgAl protease, which can cleave IgAl to Fab and Fc fragments, and can therefore eliminate the FC mediated functions of IgAl, ${ }^{82} 83$ although human secretory IgA has been shown to be resistant to this protease activity. ${ }^{84}$ It has been suggested that in mucosal secretions, IgA antibodies against protein antigens are predominantly IgAl, whereas those directed against polysaccharides are almost equally distributed between the two subclasses..$^{85-87}$

Concentrations of specific IgG in saliva and serum in individuals are usually correlated. ${ }^{25}{ }^{73}$ For this reason, salivary IgG antibodies are thought mainly to be passively derived from serum, although IgG antibodies may also be produced locally at the mucosal level. ${ }^{6488} 89$ The commonly observed close correlation between an individual's concentrations of antigen specific secretory component (secretory IgA) and specific IgA antibodies in saliva suggests that these mucosal IgA antibodies are secretory $\operatorname{Ig} \mathrm{A}$ and that their release is locally regulated. ${ }^{25} 73$

Mucosal immune systems may be anatomically and functionally divided into two separate but interconnected compartments, namely: mucosal inductive sites and effector sites. ${ }^{90}{ }^{91}$ Inductive sites include the gut associated and nasal associated lymphoreticular tissues, which are anatomically situated in the gastrointestinal tract and the nasopharyngeal area (palatine tonsils and the nasopharyngeal tonsils (adenoids)), where they encounter environmental antigens and become activated. Sensitised $\mathrm{T}$ and $\mathrm{B}$ cells migrate to effector sites such as the lamina propria of the gastrointestinal tract and upper respiratory tract and to secretory glands for subsequent antigen specific antibody responses.

The inductive and effector sites of conjugate PS vaccine induced mucosal immune responses are unknown. In the human upper respiratory tract, the palatine tonsils and the nasopharyngeal tonsils (adenoids) are the largest component of Waldeyer's ring, and are thought to be functionally related to nasal associated lymphoreticular tissue of rodents and other species. ${ }^{92}$ Adenoids and tonsils may play a role in the upper respiratory tract both as inductive sites and effector sites for both IgG and IgA antibody responses. ${ }^{93}$ Combined adenoidectomy and tonsillectomy have been reported to reduce IgA values to poliovirus in nasopharyngeal secretions and to delay or abrogate mucosal immune responses to subsequent polio vaccination, ${ }^{94}$ suggesting that these mucosal lymphoid tissues are important mucosal immune inductive and/or effector sites in the upper respiratory tract. However, these lymphoreticular tissues have unique features. B cells, in contrast to those in other mucosal compartments, are predominantly IgG rather than IgA secreting cells. ${ }^{64}{ }^{93}$ Human adenoids and tonsils contain more IgG secreting cells than do the lamina propria and Peyer's patches of the gastrointestinal tract, where most B cells secrete IgA. ${ }^{81} 95$ The localisation of IgA and large numbers of IgG secreting cells in the epithelium suggests that these tonsils have characteristics of effectors sites and that IgG could be an important component of mucosal immune defence in the upper respiratory tract. ${ }^{93}$ High IgG titres in both saliva and serum after MenC conjugate vaccination ${ }^{73}$ suggests that human adenoids and tonsils may be involved in the immune responses induced by the conjugate vaccine.

It is unclear how intramuscularly injected vaccine antigens induce upper respiratory mucosal responses. It is possible that the free vaccine antigen (with the protein carrier) is transported to and induces antigen specific antibody secreting cells in the lymphoid tissue (such as adenoids and tonsils) local to the upper respiratory tract, because injected $H$ influenzae type b PS antigen has been shown to be dispersed throughout the body. ${ }^{96}{ }^{97}$ Another possibility is that antibody secreting $\mathrm{B}$ cells produced in the peripheral draining node near the injection site migrate to the upper respiratory mucosa. ${ }^{989}$ It has been shown that antigen specific IgA secreting cells that bear the mucosal homing receptor $\alpha_{4} \beta_{7}$ can be detected in the circulation shortly after parenteral inoculation, ${ }^{100}{ }^{101}$ indicating that non-mucosal immunisation can induce effector B cells capable of homing to mucosal tissues. It has also been shown that after immunisation with pneumococcal PS vaccines, there is a positive correlation between the number of anti-pneumococcal PS IgA antibody secreting cells in blood and the IgA antibody concentrations in saliva, suggesting that the number of IgA antibody secreting cells after parenteral immunisation may be an indicator of the secretory IgA response..$^{53}$ Alternatively, or additionally, the vaccine antigen may be taken up by antigen presenting cells in the draining peripheral lymph node, which then migrate to the local lymphoid tissue (tonsils) in the upper respiratory tract and present to lymphocytes and induce antibody production there..$^{99} 102$

\section{FUTURE CONSIDERATIONS}

Although conjugate PS vaccines can induce mucosal immune responses in the upper respiratory tract and have the potential to reduce carriage and to some extent to prevent acute otitis media, their mucosal effects can perhaps be improved by optimising the dosage, dose regimen, and route of immunisation. Further studies are needed to investigate the functions and mechanisms of action of anticapsular 


\section{Take home messages}

- Nasopharyngeal carriage of pathogens is a prerequisite of infection and invasive disease and is the source of transmission

- To induce community immunity against nasopharyngeal pathogens, it is necessary to induce protection against carriage

- Local mucosal immunity within the nasopharynx may play a crucial role in the reduction of carriage

- Recently introduced polysaccharide based conjugate vaccines can induce good immune responses at the local mucosal level

- Protein vaccine candidates against nasopharyngeal pathogens have been under intensive research and some are showing great potential as mucosal vaccines

- The development of antibacterial vaccines that can be administered intranasally is an attractive idea and is the subject of current research

mucosal antibodies. New protein vaccine candidates and combinations of protein and PS antigens are currently under investigation, and have been shown to reduce nasal carriage in mice. ${ }^{103}$ It would be wise to assess the mucosal effect of candidate antigen(s) in humans as one of the selection criteria for new vaccines.

"Further studies are needed to investigate the functions and mechanisms of action of anticapsular mucosal antibodies"

The development of antibacterial vaccines that can be administered intranasally is an attractive idea because it would avoid pain, the need for equipment and skilled personnel, and the risks associated with all injections of injury and transmission of infection. Although such vaccines might be aimed primarily at the prevention of carriage and transmission, it is possible that they would also protect against invasive disease in the recipient, either by intercepting invasion at the mucosal level or by inducing systemic immunity, as is seen with oral polio vaccine, or both. However, it is probable that such mucosal vaccines will require effective biological adjuvants to be effective, and the search for such formulations adds further urgency to the need to understand how mucosal immunity works.

\section{REFERENCES}

1 King WJ, MacDonald NE, Wells G, et al. Total and functional antibody response to a quadrivalent meningococcal polysaccharide vaccine among children. J Pediatr 1996;128:196-202.

2 Granoff DM, Gupta RK, Belshe RB, et al. Induction of immunologic refractoriness in adults by meningococcal $C$ polysaccharide vaccination. $J$ Infect Dis 1998;178:870-4.

3 Brandt BL, Artenstein MS. Duration of antibody responses after vaccination with group C Neisseria meningitidis polysaccharide. J Infect Dis 1975; 131(suppl):S69-72.

4 Granoff DM, Anderson EL, Osterholm MT, et al. Differences in the immunogenicity of three Haemophilus influenzae type $b$ conjugate vaccines in infants. J Pediatr 1992;121:187-94.

5 Richmond P, Borrow R, Goldblatt D, et al. Ability of 3 different meningococcal $\mathrm{C}$ conjugate vaccines to induce immunologic memory after a single dose in UK toddlers. J Infect Dis 2001;183:160-3.

6 Schlesinger Y, Granoff DM. Avidity and bactericidal activity of antibody elicited by different Haemophilus influenzae type $b$ conjugate vaccines. The vaccine study group. JAMA 1992;267:1489-94.

7 Antrila M, Eskola J, Ahman H, et al. Differences in the avidity of antibodies evoked by four different pneumococcal conjugate vaccines in early childhood. Vaccine 1999;17:1970-7.
8 Twumasi PA Jr, Kumah S, Leach A, et al. A trial of a group A plus group C meningococcal polysaccharide-protein conjugate vaccine in African infants. $J$ Infect Dis 1995; 171:632-8.

9 Lieberman JM, Chiu SS, Wong VK, et al. Safety and immunogenicity of a serogroups $A / C$ Neisseria meningitidis oligosaccharide-protein conjugate vaccine in young children. A randomized controlled trial. JAMA 1996;275:1499-503.

10 Fairley CK, Begg N, Borrow R, et al. Conjugate meningococcal serogroup A and $C$ vaccine: reactogenicity and immunogenicity in United Kingdom infants. J Infect Dis 1996;174:1360-3.

11 Leach A, Twumasi PA, Kumah S, et al. Induction of immunologic memory in Gambian children by vaccination in infancy with a group $A$ plus group $C$ meningococcal polysaccharide-protein conjugate vaccine. $J$ Infect Dis 1997; 175:200-4.

12 Choo S, Finn A. New pneumococcal vaccines for children. Arch Dis Child 2001;84:289-94.

13 Lakshman R, Finn A. Meningococcal serogroup $C$ conjugate vaccine. Expert Opin Biol Ther 2002;2:87-96.

14 Turk DC. The pathogenicity of Haemophilus influenzae. J Med Microbiol 1984;18:1-16.

15 Glode MP, Daum RS, Boies EG, et al. Effect of rifampin chemoprophylaxis on carriage eradication and new acquisition of Haemophilus influenzae type $b$ in contacts. Pediatrics 1985;76:537-42.

16 Takala AK, Eskola J, Leinonen $M$, et al. Reduction of oropharyngeal carriage of Haemophilus influenzae type $b$ (Hib) in children immunized with an Hib conjugate vaccine. J Infect Dis 1991;164:982-6.

17 Peltola H, Kayhty H, Sivonen A, et al. Haemophilus influenzae type b capsular polysaccharide vaccine in children: a double-blind field study of 100,000 vaccinees 3 months to 5 years of age in Finland. Pediatrics 1977;60:730-7.

18 Murphy TV, Pastor P, Medley F, et al. Decreased haemophilus colonization in children vaccinated with Haemophilus influenzae type $b$ conjugate vaccine. J Pediatr 1993;122:517-23.

19 Takala AK, Santosham M, Almeido-Hill J, et al. Vaccination with Haemophilus influenzae type $b$ meningococcal protein conjugate vaccine reduces oropharyngeal carriage of Haemophilus influenzae type b among American Indian children. Pediatr Infect Dis J 1993;12:593-9.

20 Barbour ML, Mayon-White RT, Coles C, et al. The impact of conjugate vaccine on carriage of Haemophilus influenzae type $b$. J Infect Dis 1995;171:93-8.

21 Mohle-Boetani JC, Ajello G, Breneman E, et al. Carriage of Haemophilus influenzae type $b$ in children affer widespread vaccination with conjugate Haemophilus influenzae type b vaccines. Pediatr Infect Dis J 1993;12:589-93.

22 Pichichero ME, Hall CB, Insel RA. A mucosal antibody response following systemic Haemophilus influenzae type B infection in children. J Clin Invest 1981:67:1482-9.

23 Pichichero ME, Insel RA. Mucosal antibody response to parenteral vaccination with Haemophilus influenzae type b capsule. J Allergy Clin Immunol 1983;72:481-6.

24 Gilsdorf JR, McDonnell WM. Mucosal antibodies to Haemophilus influenzae type b capsular polysaccharide. Pediatr Res 1991;29:420-3.

25 Kauppi M, Eskola J, Kayhty H. Anti-capsular polysaccharide antibody concentrations in saliva after immunization with Haemophilus influenzae type b conjugate vaccines. Pediatr Infect Dis J 1995;14:286-94.

26 Kauppi M, Saarinen L, Kayhty H. Anti-capsular polysaccharide antibodies reduce nasopharyngeal colonization by Haemophilus influenzae type $b$ in infant rats. J Infect Dis 1993;167:365-71.

27 Kauppi-Korkeila M, van Alphen L, Madore D, et al. Mechanism of antibodymediated reduction of nasopharyngeal colonization by Haemophilus influenzae type b studied in an infant rat model. J Infect Dis 1996; 174:1337-40.

28 van Alphen L, Eijk P, Kayhty H, et al. Antibodies to Haemophilus influenzae type $b$ polysaccharide affect bacterial adherence and multiplication. Infect Immun 1996;64:995-1001.

29 Finn $A$, Zhang $Q$, Seymour $L$, et al. Induction of functional secretory $\lg A$ responses in breast milk by pneumococcal capsular polysaccharides. J Infect Dis 2002;186:1422-9.

30 Janoff EN, Fasching C, Orenstein JM, et al. Killing of Streptococcus pneumoniae by capsular polysaccharide-specific polymeric lgA, complement, and phagocytes. J Clin Invest 1999; 104:1139-47.

31 Forsgren J, Samuelson A, Ahlin A, et al. Haemophilus influenzae resides and multiplies intracellularly in human adenoid tissue as demonstrated by in situ hybridization and bacterial viability assay. Infect Immun 1994;62:673-9.

32 Dagan R, Melamed R, Muallem M, et al. Nasopharyngeal colonization in southern Israel with antibiotic-resistant pneumococci during the first 2 years of life: relation to serotypes likely to be included in pneumococcal conjugate vaccines. J Infect Dis 1996;174:1352-5.

33 Zenni MK, Cheatham SH, Thompson JM, et al. Streptococcus pneumoniae colonization in the young child: association with otitis media and resistance to penicillin. J Pediatr 1995; 127:533-7.

34 Virolainen A, Vero J, Kayhty $\mathrm{H}$, et al. Nasopharyngeal antibodies to pneumococcal capsular polysaccharides in children with acute otitis media. $J$ Infect Dis 1995;172:1115-18.

35 Simell B, Kilpi TM, Kayhty H. Pneumococcal carriage and otitis media induce salivary antibodies to pneumococcal capsular polysaccharides in children. $\mathrm{J}$ Infect Dis 2002;186:1106-14.

36 Nieminen T, Virolainen A, Kayhty H, et al. Antibody-secreting cells and their relation to humoral antibodies in serum and in nasopharyngeal aspirates in children with pneumococcal acute otitis media. $J$ Infect Dis 1996;173:136-41. 
37 Makela $\mathrm{PH}$, Sibakov M, Herva $\mathrm{E}$, et al. Pneumococcal vaccine and otitis media. Lancet 1980;2:547-51.

38 Teele DW, Klein JO, Bratton L, et al. Use of pneumococcal vaccine for prevention of recurrent acute otitis media in infants in Boston. The greater Boston collaborative otitis media study group. Rev Infect Dis 1981;3(suppl):S113-18.

39 Howie VM, Ploussard J, Sloyer JL, et al. Use of pneumococcal polysaccharide vaccine in preventing otitis media in infants: different results between racial groups. Pediatrics 1984;73:79-81.

40 Douglas RM, Miles HB. Vaccination against Streptococcus pneumoniae in childhood: lack of demonstrable benefit in young Australian children. J Infect Dis 1984; 149:861-9

41 Black S, Shinefield H, Fireman B, et al. Efficacy, safety and immunogenicity of heptavalent pneumococcal conjugate vaccine in children. Northern California Kaiser Permanente vaccine study center group. Pediatr Infect Dis J 2000; 19:187-95.

42 Eskola J, Kilpi T, Palmu A, et al. Efficacy of a pneumococcal conjugate vaccine against acute otitis media. N Engl J Med 2001:344:403-9.

43 Kilpi T, Ahman H, Jokinen J, et al. Protective efficacy of a second pneumococcal conjugate vaccine against pneumococcal acute otitis media in infants and children: randomized, controlled trial of a 7-valent pneumococcal polysaccharide-meningococcal outer membrane protein complex conjugate vaccine in 1666 children. Clin Infect Dis 2003;37:1155-64.

44 Veenhoven R, Bogaert D, Uiterwaal C, et al. Effect of conjugate pneumococcal vaccine followed by polysaccharide pneumococcal vaccine on recurrent acute otitis media: a randomised study. Lancet 2003:361:2189-95.

45 Douglas RM, Hansman D, Miles HB, et al. Pneumococcal carriage and typespecific antibody. Failure of a 14 -valent vaccine to reduce carriage in healthy children. Am J Dis Child 1986;140:1183-5.

46 Klugman KP, Madhi SA, Huebner RE, et al. A trial of a 9-valent pneumococcal conjugate vaccine in children with and those without HIV infection. N Engl J Med 2003;349:1341-8.

47 Obaro SK, Adegbola RA, Banya WA, et al. Carriage of pneumococci after pneumococcal vaccination. Lancet 1996;348:271-2.

48 Dagan R, Muallem M, Melamed R, et al. Reduction of pneumococcal nasopharyngeal carriage in early infancy after immunization with tetravalent pneumococcal vaccines conjugated to either tetanus toxoid or diphtheria toxoid. Pediatr Infect Dis J 1997;16:1060-4.

49 Mbelle N, Huebner RE, Wasas AD, et al. Immunogenicity and impact on nasopharyngeal carriage of a nonavalent pneumococcal conjugate vaccine. $J$ Infect Dis 1999;180:1171-6.

50 Dagan R, Fraser D. Conjugate pneumococcal vaccine and antibiotic-resistant Streptococcus pneumoniae: herd immunity and reduction of otitis morbidity. Pediatr Infect Dis J 2000;19:S79-88.

51 Whitney CG, Farley MM, Hadler J, et al. Decline in invasive pneumococcal disease after the introduction of protein-polysaccharide conjugate vaccine. $N$ Engl J Med 2003;348:1737-46.

52 Choo S, Zhang Q, Seymour L, et al. Primary and booster salivary antibody responses to a 7 -valent pneumococcal conjugate vaccine in infants. $J$ Infect Dis 2000;182:1260-3

53 Nieminen T, Kayhty $\mathrm{H}$, Leroy $\mathrm{O}$, et al. Pneumococcal conjugate vaccination in toddlers: mucosal antibody response measured as circulating antibodysecreting cells and as salivary antibodies. Pediatr Infect Dis J 1999:18:764-72.

54 Nurkka A, Ahman H, Yaich $M$, et al. Serum and salivary anti-capsular antibodies in infants and children vaccinated with octavalent pneumococcal conjugate vaccines, PncD and PncT. Vaccine 2001;20:194-201.

55 Nurkka A, Ahman $\mathrm{H}$, Korkeila $M$, et al. Serum and salivary anti-capsular antibodies in infants and children immunized with the heptavalent pneumococcal conjugate vaccine PncCRM. Pediatr Infect Dis J $2001 ; 20: 25-33$.

56 Korkeila $\mathrm{M}$, Lehtonen $\mathrm{H}$, Ahman $\mathrm{H}$, et al. Salivary anti-capsular antibodies in infants and children immunised with Streptococcus pneumoniae capsular polysaccharides conjugated to diphtheria or tetanus toxoid. Vaccine 2000; 18:1218-26

57 Zhang Q, Arnaoutakis K, Murdoch C, et al. Mucosal immune responses to capsular polysaccharides in immunized pre-school children and controls with similar nasal pneumococcal colonization rates. Pediatr Infect Dis J 2004;23:307-13.

58 Lakshman R, Murdoch C, Race G, et al. Pneumococcal nasopharyngeal carriage in children following heptavalent pneumococcal conjugate vaccination in infancy. Arch Dis Child 2003:88:211-14.

59 Paton JC. Novel pneumococcal surface proteins: role in virulence and vaccine potential. Trends Microbiol 1998;6:85-7.

60 Briles DE, Hollingshead S, Brooks-Walter A, et al. The potential to use PspA and other pneumococcal proteins to elicit protection against pneumococcal infection. Vaccine 2000;18:1707-11.

61 Briles DE, Ades E, Paton JC, et al. Intranasal immunization of mice with a mixture of the pneumococcal proteins PsaA and PspA is highly protective against nasopharyngeal carriage of Streptococcus pneumoniae. Infect Immun 2000:68:796-800.

62 Rapola S, Jantti V, Haikala R, et al. Natural development of antibodies to Pneumococcal surface protein $A$, pneumococcal surface adhesin $A$, and pneumolysin in relation to pneumococcal carriage and acute otitis media. $J$ Infect Dis 2000;182: 1146-52.

63 Simell B, Korkeila M, Pursiainen $\mathrm{H}$, et al. Pneumococcal carriage and otitis media induce salivary antibodies to pneumococcal surface adhesin $A$, pneumolysin, and pneumococcal surface protein $A$ in children. J Infect Dis 2001;183:887-96.
64 Zhang Q, Choo S, Finn A. Immune responses to novel pneumococcal proteins (pneumolysin, PspA, PsaA and CbpA) in adenoidal B cells from children. Infect Immun 2002;70:5363-9.

65 McCool TL, Cate TR, Moy G, et al. The immune response to pneumococcal proteins during experimental human carriage. J Exp Med 2002; 195:359-65.

66 Rake G. Studies on meningococcus infection. VI. The carrier problem. J Exp Med 1934;59:553

67 Glover JA. The cerebrospinal fever epidemic of 1917 at " $X$ " depot. Journal of American Army Medical Corps 1918;30:23.

68 MacLennan JM, Shackley F, Heath PT, et al. Safety, immunogenicity, and induction of immunologic memory by a serogroup $C$ meningococca conjugate vaccine in infants: a randomized controlled trial. JAMA 2000;283:2795-801.

69 MacLennan J, Obaro S, Deeks J, et al. Immunologic memory 5 years after meningococcal $\mathrm{A} / \mathrm{C}$ conjugate vaccination in infancy. J Infect Dis 2001;183:97-104.

70 MacDonald NE, Halperin SA, Law BJ, et al. Induction of immunologic memory by conjugated vs plain meningococcal $C$ polysaccharide vaccine in toddlers: a randomized controlled trial. JAMA 1998;280:1685-9.

71 Ramsay M, Andrews N, Kaczmarski EB, et al. Efficacy of meningococcal serogroup c conjugate vaccine in teenagers and toddlers in England. Lancet 2001;357:195-6.

72 Maiden MC, Stuart JM, The UK Meningococcal Carraige Group. Carriage of serogroup $C$ meningococci 1 year after meningococcal $C$ conjugate polysaccharide vaccination. Lancet 2002:359:1829-31.

73 Zhang Q, Choo S, Everard J, et al. Mucosal immune responses to meningococcal group $C$ conjugate and group $A$ and $C$ polysaccharide vaccines in adolescents. Infect Immun 2000;68:2692-7.

74 Zhang Q, Lakshman R, Burkinshaw R, et al. Primary and booster mucosal immune responses to meningococcal group $A$ and $C$ conjugate and polysaccharide vaccines administered to university students in the United Kingdom. Infect Immun 2001;69:4337-41.

75 Zhang Q, Pettitt E, Burkinshaw R, et al. Mucosal immune responses to meningococcal conjugate polysaccharide vaccine in infants. Pediatr Infect Dis J 2002;21:209-13.

76 Borrow R, Fox AJ, Cartwright K, et al. Salivary antibodies following parenteral immunization of infants with a meningococcal serogroup $A$ and $C$ conjugated vaccine. Epidemiol Infect 1999;123:201-8.

77 Borrow R, Goldblatt D, Finn A, et al. Immunogenicity of, and immunologic memory to, a reduced primary schedule of meningococcal C-tetanus toxoid conjugate vaccine in infants in the United Kingdom. Infect Immun 2003:71:5549-55

78 Finn A, Seymour L, Arnaoutakis K, et al. One dose of MenC-T conjugate vaccine in infancy produces higher mucosal $\lg G$ and $\lg A$ responses than 2 or 3 doses and optimal mucosal booster responses following polysaccharide vaccine at 13 months. Arch Dis Child 2002;86:A69.

79 Nurkka A, MacLennan J, Jantti V, et al. Salivary antibody response to vaccination with meningococcal $A / C$ polysaccharide vaccine in previously vaccinated and unvaccinated Gambian children. Vaccine 2000; 19:547-56.

80 Kauppi-Korkeila M, Saarinen L, Eskola J, et al. Subclass distribution of IgA antibodies in saliva and serum after immunization with Haemophilus influenzae type b conjugate vaccines. Clin Exp Immunol 1998; 11 1:237-42.

81 Mestecky J, McGhee JR. Immunoglobulin A (lgA): molecular and cellular interactions involved in IgA biosynthesis and immune response. Adv Immunol 1987:40:153-245

82 Kilian M, Mestecky J, Russell MW. Defense mechanisms involving Fcdependent functions of immunoglobulin $A$ and their subversion by bacterial immunoglobulin A proteases. Microbiol Rev 1988;52:296-303

83 Plaut AG. The lgAl proteases of pathogenic bacteria [review]. Annu Rev Microbiol 1983:37:603-22.

84 Gilbert JV, Plaut AG, Longmaid B, et al. Inhibition of microbial lgA proteases by human secretory IgA and serum. Mol Immunol 1983;20:1039-49.

85 Brown TA, Mestecky J. Immunoglobulin A subclass distribution of naturally occurring salivary antibodies to microbial antigens. Infect Immun 1985;49:459-62.

86 Brown TA, Murphy BR, Radl J, et al. Subclass distribution and molecular form of immunoglobulin $A$ hemagglutinin antibodies in sera and nasal secretions after experimental secondary infection with influenza $A$ virus in humans. J Clin Microbiol 1985;22:259-64.

87 Ladjeva I, Peterman JH, Mestecky J. IgA subclasses of human colostral antibodies specific for microbial and food antigens. Clin Exp Immunol 1989;78:85-90

88 Ferrero RL, Thiberge JM, Labigne A. Local immunoglobulin $G$ antibodies in the stomach may contribute to immunity against Helicobacter infection in mice. Gastroenterology 1997;113:185-94

89 Walker MJ, Rohde M, Timmis KN, et al. Specific lung mucosal and systemic immune responses after oral immunization of mice with Salmonella typhimurium aroA, Salmonella typhi Ty2la, and invasive Escherichia coli expressing recombinant pertussis toxin $\mathrm{S} 1$ subunit. Infect Immun 1992;60:4260-8.

90 McGhee JR, Mestecky J, Dertzbaugh MT, et al. The mucosal immune system: from fundamental concepts to vaccine development [review]. Vaccine 1992;10:75-88

91 Kiyono H, Bienenstock J, McGhee JR, et al. The mucosal immune system: features of inductive and effector sites to consider in mucosal immunization and vaccine development [review]. Reg Immunol 1992;4:54-62.

92 Kuper CF, Koornstra PJ, Hameleers DM, et al. The role of nasopharyngeal lymphoid tissue [see comments] [review]. Immunol Today 1992;13:219-24. 
93 Boyaka PN, Wright PF, Marinaro M, et al. Human nasopharyngealassociated lymphoreticular tissues. Functional analysis of subepithelial and intraepithelial B and T cells from adenoids and tonsils. Am J Pathol 2000;157:2023-35.

94 Ogra PL. Effect of tonsillectomy and adenoidectomy on nasopharyngeal antibody response to poliovirus. $N$ Engl J Med 1971;284:59-64.

95 Fujihashi K, McGhee JR, Lue C, et al. Human appendix B cells naturally express receptors for and respond to interleukin 6 with selective $\lg \mathrm{A} 1$ and $\lg$ A2 synthesis. J Clin Invest 1991;88:248-52.

96 Spinola ST, Sheaffer Cl, Philbrick KB, et al. Antigenuria after Haemophilus influenzae type b polysaccharide immunisation: a prospective study. J Pediatr 1986; 108:247-9.

97 Darville T, Jacobs RF, Lucas RA, et al. Detection of Haemophilus influenzae type $b$ antigen in cerebrospinal fluid after immunisation. Pediatr Infect Dis $J$ 1992;11:243-4. 98 Mestecky J, Russell MW. IgA subclassess. Monogr Allergy
1986;19:277-301.
99 Brokstadt KA, Cox RJ, Olofsson J, et al. Parenteral influenza vaccination induces a rapid systemic and local immune response. J Infect Dis 1995; 171:198-203.

100 Quiding-Jabrink M, Nordstrom I, Granstrom G, et al. Differential expression of tissue-specific adhesion molecules on human circulating antibody-forming cells after systemic, enteric, and nasal immunisation. J Clin Invest 1997;99:1281-6.

101 Kantele A, Kantel JM, Savilathi E, et al. Homing potential of circulating lymphocytes in humans depend on the site of activation: oral, but not parenteral, typhoid vaccination induces circulating antibody-secreting cells that all bear homing receptors directing them to the gut. J Immunol 1997; 158:574-9.

102 Coffin SE, Clark SL, Bos NA, et al. Migration of antigen-presenting B cells from peripheral to mucosal lymphoid tissues may induce intestinal antigenspecific IgA following parenteral immunization. J Immunol 1999; 163:3064-70.

103 Paton JC. Novel pneumococcal surface proteins: role in virulence and vaccine potential. Trends Microbiol 1998;6:85-7.

\section{$\mathrm{ECHO}$}

\section{$T$ vaginalis screening goes global}

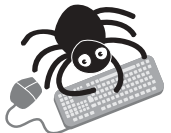

Please visit the Journal of Clinical Pathology website [www. jclinpath.com] for a link to the full text of this article.
A large study in Africa could help to control the HIV epidemic there, through routine screening for Trichomonas vaginalis, which can predispose to HIV infection. The study concluded that a latex agglutination test, by virtue of its simplicity, is a realistic prospect for screening in poor countries.

Sensitivity of the test was higher than for "wet preparation"-microscopic examination of a vaginal swab sample (98.8 v 81.5) - and equivalent to culture (98.2) - the definitive test for $T$ vaginalis. Specificity, at 92.1, was satisfactory. Agreement between latex agglutination and the other tests was good (0.93 agglutination/culture; 0.88 agglutination/wet preparation). The test requires minimal equipment and training; results are available within two minutes.

Vaginal swab samples were taken by a nurse from all 206 women positive for T vaginalis by latex agglutination of initial samples obtained themselves and 412 selected women with negative initial samples out of 3807 consecutive women attending antenatal clinics in Ghana between September 2002 and May 2003. Wet preparation and culture were performed by experienced staff, and all results were read independently and blind.

A simple, rapid test is needed in developing countries, where $T$ vaginalis infection is most prevalent. Infection increases HIV transmission, but its treatment reduces viral load in vaginal and seminal fluid. Therefore identifying and treating $\mathrm{T}$ vaginalis-whose rate of new infections is an estimated 170 million/year-should curb spread of HIV. "It is time to evolve routine screening and treatment for $T$ vaginalis infection in reproductive health settings,"say the authors.

A Adu-Sarkodie Y, et al. Sexually Transmitted Infections 2004;80:201-203. 